\title{
Bapsi Sidhwa's Ice-Candy-Man and its Film Version: An Insight
}

\author{
Shalini Pandey \\ Assistant Professor \\ Department of English, Govt. T. C. L. P.G. College Janjgir (C.G.) \\ Email-shalinipandeyenglishap@gmail.com
}

\begin{abstract}
:
Deepa Mehta's adaptation of Bapsi Sidhwa's novel Ice Candy Man (a literary text) into a film Earth (a visual text) is an exceptional example of a hybrid representation. Deepa Mehta adapted Ice Candy Man into a film 1947: Earth. Making a novel into a film is a difficult task. A director's ability to transform words into moving visuals is exceptional. There is a transition in narratology as the novel is transformed into the film. Deepa Mehta sets herself a difficult task in producing Earth, translating Sidhwa's amazing story into a film using cinematic skills and artistry. The purpose of this article is to compare and contrast Bapsi Sidhwa's novel Ice Candy Man and its cinematic adaptation Deepa Mehta's "1947: Earth" in order to investigate the problem of depicting the Partition of India in 1947.
\end{abstract}

Key words: Literary Text, Visual Text, Adaptation, Cinematic tools, Partition, violent ramifications.

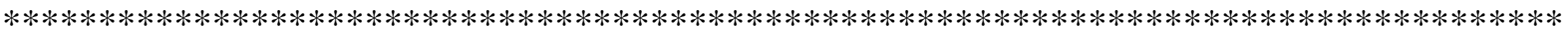

The relationship between film and novel is perhaps over a century old. In reality, the number of novels that have been adapted into films is limitless. Michael, a cinema historian remarks: "A Film is a cinematographic representation of a story, drama, episode, event, etc. that is shaped, angled, finite, intended, whether it is a document or an art installation, a bit of gritty realism, or a full-blown fantasy." (p. 114)

Ice Candy Man was written by Bapsi Sidhwa in 1988. The book was published in the United States as Cracking India in1991. In 1998, Deepa Mehta directed 1947: Earth, a film based on the novel. The novel Ice-Candy-Man depicts people from all walks of life in Lahore before Partition, including Hindus, Muslims, Sikhs, and Parsis. Bapsi Sidhwa uses the child-narrator device in this scene. Lenny, an eight-year-old girl, tells her story from the perspective of a child.

Earth is a 1999 Indo-Canadian period romance drama film directed by Deepa Mehta that was released in India as "1947: Earth". Which is set during India's 1947 partition. Earth is the second volume in Mehta's Elements trilogy, which began with Fire in 1996 and ended with Water in 2005. 1947: Earth was India's entry for the Best Foreign Language Film Oscar in 1999. Earth deals with abuse against women during partition of India. Deepa Mehta, adapted the print for the silver screen, starring Aamir Khan and Nandita Das. The film premiered in 
September 1998 at the Toronto International Film Festival; it was released in India and the United States in 1999, and it has subsequently been screened in England, Australia, and France. It elicited a wide range of reactions in various regions, ranging from emotionally moved and joyful to uninterested and critical.

The two names of novel allude to various interpretations and reactions to the novel's central topic, which reflects the agony and chaos that greeted freedom in 1947. Bapsi Sidhwa book is also about betrayal, a country being deceived, as well as Lenny's betrayal of her ayah, the latter to become a microcosmic symbol of the divisions, chaos, and confusion that engulfed undivided India in the run-up to August 1947 in the novel and completely in Deepa Mehta's film.

Because a visual adaptation of a literary text is a complicated phenomenon involving the fundamental paradox of word and image, some compression and deletion is inevitable when linguistic signs are translated into visual signs. The reinterpretation, modulation, adaptation, or reassessment of the meaning of earlier literary texts may result from the visual adaptation of a literary text. Although the division of the Indian subcontinent has received widespread attention in literature, major cinema and academia have remained relatively silent on the subject.

Before making a comparison between the novel and the movie, it is important to know about Sidhwa and Deepa Mehta. Because of Bapsi Sidhwa's unique position as a Parsee Pakistani diasporic writer outside of the Hindu-Muslim-Sikh split, Bapsi Sidhwa is able to document Pakistan's creation in a unique way. Lenny, like Sidhwa, is a privileged child, born into an upper-middle-class Parsee household, and is thus a doubly "neutral" storyteller, due to her age and ethnic-religious identity. Deepa Mehta, on the other hand, was born into a Hindu community in Amritsar and moved to Canada with her family during Partition. She began making movie "Earth" in 1997, the fiftieth anniversary of the Division, with the historical backdrop of that year. As a result, Earth took part in a moment of collective remembrance that had a nationalist bent to it. Ethnic politics also play a part in the shaping and creation of each piece. Adapting Ice-Candy-Man into movie "Earth" has numerous fascinating additions as well as exclusions in Deepa Mehta's rendition. The transition from a young Lenny describing the novel to an adult voiceover as the film's narrator foreshadows the kinds of shifts that would occur in Mehta's film. Because of the differences between textual and visual and auditory mediums, certain exclusions become necessary when translating a novel to the screen.

Ice-Candy-Man is a novel by Bapsi Sidhwa that attempts to review or rewrite the history of Partition by giving voice to marginalised groups on gender, class, ethnicity, and nationality. To displace or contradict the discursive tendencies of historical thought in Europe or India, Sidhwa examines the history of Partition from a more or less feminist and Pakistani perspective. Unlike the novel, 1947: Earth can be seen as part of grand narratives of communal violence and human nature. In terms of broad narrative and dialogue, the movie's cinematic adaptation largely follows the novel Ice-Candy-Man. However, because cinema is a distinct medium with its own worries about economics, authorship, production, distribution, and reception, some of the novel's issues are ignored while others are highlighted. From this viewpoint. Bapsi Sidhwa's 
novel Ice Candy Man is one of the few novels to capture the agitation of the Indian subcontinent during partition with such immediacy and tragic power. According to Novy Kapadiya: "IceCandy Man is a novel of upheaval which includes a cast of characters from all communities..., so a multiple perspective of Partition emerges as viewed by all the affected communities" (Kapadia35).

This novel is said to have a more touching, convincing, horrifying, compelling, and illuminating perspective on Partition, one of the most horrifying events in world history. Afreen Faiyaz writes "The central consciousness of the fictional world of Ice-Candy-Man is represented by a young girl, Lenny, who is lame. The lameness of the narrator becomes suggestive of the handicap a woman creative writer faces, when she decides to wield the pen, because writing, being an intellectual exercise, is considered a male bastion, outside the routine of a woman's submissive domesticity. Her recuperation symbolizes the overcoming of the constraint on the intellectual activity of writing by Bapsi Sidhwa. By making Lenny the narrator of the novel, the novelist lends weight and validity to the feminine perspective on the nature of surrounding reality." ( Faiyaz 35).

Both Sidhwa and Mehta depict Ayah's transformation from the centre of interest to a victim of abduction and rape in their depictions of the Partition. Lenny tells how Ayah attracts "covetous glances" from a range of men beggars, religious men, hawkers, and so on in the beginning of the novel. "Stub- handed wasted beggars and dusty old beggars on crutches drop their poses and stare at her with hard, alert eyes. Holy men, masked in piety, shove aside their pretences to ogle her with lust. Hawkers, cart drivers, cooks, coolies and cyclists turn their heads as she passes, pushing my pram with the unconcern of the Hindu goddess she worships" (Sidhwa 3).

Applauding Bapsi Sidhwa for her novel, Shashi Tharoor says "In reducing partition to the perceptions of a polio-ridden child, a girl who tries to wrench out her tongue because it is unable to lie, Bapsi Sidhwa has given us in "Cracking India" a memorable book, one that confirms her reputation as Pakistan's finest English-language novelist."

In one of her interviews, Deepa Mehta says that Sidhwa's story is compelling and that it complements her filmmaking style. In fact, she is so taken aback by her unexpected discovery that she wishes to show the violent partition scenes in her film 1947: Earth: "The partition of India was like a Holocaust for us and I grew up hearing many stories about this terrible event. Naturally I was attracted to this subject" (Phillips 1).

Deepa Mehta's film Earth, does not depict what happens to Ayah after she is kidnapped. Following the kidnapping sequence, the film ends with a shot of an older Lenny in the Queen's Garden, with her voiceover saying, "I never set eyes on her again." However, Cracking India depicts Ayah's life after her kidnapping, including her time in a Lahore's brothel Heera mandi and her rescue by Lenny's mother Mrs Sethi and Godmother Rodabai. Kavita Daiya says of the movie Earth's ending, "Earth, thus, reproduces the very silences that feminist historians and anthropologists like Urvashi Butalia, Ritu Menon and Kamla Bhasin have encountered in their 
attempt to recover and record oral testimonies about the experience of abduction and sexual violence by female survivors" (62).

In her book Violent Belongings, Kavita Daiya criticises the film. She claimed that the film fails to adequately reflect the novel, which has two plot lines: "one is the story of the domestic, everyday conflicts and concerns that mark Lenny's coming of age; the second is the story of how partition, ethnic violence and migration dramatically change the lives and relationships centred upon Lenny's Hindu nanny, Ayah" (58).

Deepa Mehta, one of the most well-known diasporic film directors, has always been the type to tackle contentious and thought-provoking subjects in her films. Her critics agree that she has an odd sense of taste. Her films show that she chose controversial subjects and largerthan-life characters to express her point of view. In all of its colours, Mehta's "1947: Earth" depicts the gloomy and terrible phase of violence, brutality, rape, and massacre in Indian literature throughout the 1947s. Fundamentalist Hindus caused a massive pandemonium prior to the film's premiere date, causing resistance and turmoil. We see how the community struggles for its life during partition via the eyes of Lenny, an eight-year-old Parsi child, and how, later, when the flames of communal violence have died down, this community becomes the saviour of the victims in Ice Candy Man. The Parsi features and Parsi as an 'Other' in an established environment are compared in Ice Candy Man and "1947: Earth". As a result, Mehta, like Sidhwa, tries to give his much-hyped film a diasporic flavour. According to Jeanette Herman, "...Earth emerges in a kind of memory work, using the mode of film melodrama to participate in an attempt to enlist an effective form of public participation in a transnational moment of remembering Partition." (109)

Like Bapsi Sidhwa's novel Ice Candy Man, the film "1947: Earth" is a collection of memories from a Parsi woman. Recollections of what had changed her life, of what she had lost when she was eight years old. Shabana Azami's amazing voice as a grown-up Lenny in the outset and then in the end transports viewers to Lahore (then India) in the early half of 1947, several months before Partition. The director aims to depict what the subcontinent was going through by using Lenny as the participant protagonist and her personal observations she had at the time. Jeanette Herman asserts, “...Earth emerges in a kind of memory work, using the mode of film melodrama to participate in an attempt to enlist an effective form of public participation in a transnational moment of remembering Partition." (109)

Both the film "1947: Earth" and the "Ice-Candy-Man" employ different tools to portray the same theme. The novel employs symbols, similes, metaphors, allusions, paradoxes, and irony, whereas the film employs frame, shot, freeze, fades, voice-overs, colour, sound, light, and music among other cinematic devices. As the novel Ice-Candy-Man is turned into the film "1947: Earth", few changes are unavoidable due to the medium shift. In their novels and films, both Sidhwa and Mehta made excellent use of the many techniques.

Bapsi Sidhwa and Deepa Mehta achieved similar results despite using different mediums of expression. They are artists who have a common objective. Both artists give female victims of 
the division a voice. Both focus on the female perspective. Women are at the centre of both the narrative and the film. Sidhwa and Mehta are both multi-national artists. Sidhwa belongs to the entire world, not just Pakistan, India, and the United States. So does Deepa Mehta, who, according to her interviewer Richard Phillip, is a global citizen. Neither an Indian nor a Canadian. Women's plight and status differ from one culture to the next. Many important concepts have been examined and defended in Bapsi Sidhwa's Ice Candy Man and Deepa Mehta's “1947: Earth". The reader's attention is drawn to the underlying issue of a woman's identity and plight. Women face a variety of problems in their lives and continue on their path ignorant to their fate.

Ice-Candy-Man and "1947: Earth", the novel and the film, have significant parallels. Mehta has captured the novel's heart and soul in exquisite detail. Both Sidhwa and Mehta are strong advocates for women's rights. They hold one other in high regard. Both are influenced by the work of the other. India's partition is a central element in both the literature and the film. Both could not turn away from the 1947 division, which resulted in the world's largest human movement, as well as ethnic bloodshed, kidnappings, murders, and rapes. Both championed the cause of women, but with distinct methods. Bapsi Sidhwa employs the artistry of her writing, while Deepa Mehta employs the enchantment of her camera.

“1947: Earth" by Deepa Mehta is a horrific story about four young characters in Lahore, three of them are male and one of whom is a female known as Ayah or nanny in the Lahore's Parsi family. In fact, the men shown are well-known in their fields: Masseur, Ice-Candy Man, and Gardener, to name a few. "1947: Earth" bears witness to the three men's friendship as the evil of partition rears its ugly head in front of their eyes. As they must balance the changing partition scenario, their fraternity, political ideas, and religious principles are put to the test. Deepa Mehta, like Bapsi Sidhwa, champions strong female characters who stand up to men's discrimination against women. They believe in societal equality and peace between men and women. The women in Sidhwa's novel are aware of their rights and are working to correct them. She chose a polio-ridden Parsi girl to tell the horrible partition story based on her own personal experiences. The opposition, subordination, and oppression that creative women writers confront is referred to as lameness of protagonist Lenny. Lenny's talk with her Godmother Rodabai reveals her emotional attitude: "What a fallen woman? I ask godmother... Hamida (the second Ayah) was kidnapped by the Sikhs, Says godmother seriously... When that happens sometimes, the husband - or his family won't take her back. Why? It isn't her fault she was kidnapped. Some folk feel that way - they can't stand their women being touched by other men.” (Sidhwa 215)

Although Deepa Mehta has derived some narrative skill from Sidhwa's novel, her biggest accomplishment is her projection style of showing her characters through the strong storyline. Every frame of the film is meticulously planned by her. Every frame is necessary and contributes to the film's spontaneity. As a result, she keeps her originality and creativity to emphasise her version of 'partition.' As a result, this study relates Bapsi Sidhwa's and Deepa Mehta's efforts on women's rights to their traumatic experiences during the partition. 
To sum up, while Bapsi Sidhwa depicts both the violent ramifications on men and women's bodies all through Partition and the numerous and fun - loving forms of body aspirations in Ice-Candy-Man. Deepa Mehta's conventional feminist point of view of demarcating violence towards women and men's bodies obfuscates her ability to see Sidhwa's novel beyond the structure of nationalist violence. However, she skilfully refashions the novel's essence with her own perspective and instruments in order to retell the story of body, boundary, and treachery in a strong way. In Ice-Candy-Man we get variety of depiction of playful kinds of body desire as well as violence against men and women's bodies during the Partition, whereas Mehta's 1947: Earth depicts brutality against the body within the context of nationalist violence.

Every tragedy, on the other hand, has a good aspect in that it teaches us what we should not do. When Ice-Candy-Man Dilnawaz is cruelly beaten by the authorities for his crime of kidnapping women and running Kotha in HiraMandi, Lenny sees him with broken limbs and a dusty face. Ayah is set free from his oppression and sent to a rehabilitation centre for a period of time before being moved to India. Whereas, the film '1947: Earth' finishes with Adult Lenny Sethi receiving the news that her Ayah Shanta is in Amritsar, and Ice Candy Man Dilnawaz departing Lahore via the Wagha border to be with his her. The conclusion of both genres that is movie and novel is positive, implying that "virtue is rewarded and evil is punished."

\section{References:}

1. Butalia, Urvashi. The other side of silence: Voices from the partition of India. Penguin UK, 2017

2. Chandra, Subhash. "Ice-Candy-Man: A Feminist Perspective." The Novels of Bapsi Sidhwa. New Delhi: Prestige Books,1996. pp.176.

3. Daiya, Kavita. Violent Belongings; Partition, Gender, and National Culture in Postcolonial India Philadelphia: Temple UP, 2008. Print.

4. Earth. Dir. Deepa Mehta. Prod. Anne Masson, and Deepa Mehta. Perf. Aamir Khan, Maia Sethna, and Nandita Das.1999. Film.

5. Faiyaz, Afreen. Thematic Concerns in the Novels of Bapsi Sidhwa Lambert Academic publishing. Berlin, 2012.pp. 35

6. Havan, Araz. "Books vs. Movies Adaptations: The Never-Ending Debate". Daily Collegian. 12th March 2013. Web.9 July 2015

http://dailycollegian.com/2013/03/12/booksvs-movies-adaptations-the-never- ending-debate

7. Herman, Jeanette. "Memory and Melodrama: The Transnational Politics of Deepa Mehta." Camera Obscura 20.1 (2005): 106-147.

8. Jajja, A. (2012). "Portrayal of Partition by Bapsi Sidhwa and Khushwant Singh: A Comparative Study" Pakistan Journal of Social Sciences. vol. 32, No.1,2012,pp.209-220. https://www.bzu.edu.pk/PJSS/Vol32No12012/Final_PJSS-32-1-16.pdf

9. Menon, Ritu and Bhasin, Kamala. Borders and Boundaries: Women in India's Partition. New Delhi: Women Unlimited, 2004. Print.

10. Orme, Michael. "The Bookshelf and the Screen" Illustrated London News, CLXXXVI 10 March 1934. 29 March 2016. Web. 368.

11. Sidhwa, Bapsi. Ice-Candy-Man, New Delhi, Penguin Books, 1989. 